\title{
Methods of Increasing Productivity of Material Layerwise Synthesis Based on Melting Wire Filler by Electric Arc in Vacuum
}

\author{
Dmitriy Nikolaevich Trushnikov ${ }^{1}$, Yuri Dmitrievich Shchitsyn ${ }^{1}$, Dmitry Sergeevich Belinin ${ }^{1}$, Igor Bezukladnikov ${ }^{1}$, \\ Uwe Reisgen $^{2}$, Elena Georgieva Koleva ${ }^{3}$ \\ ${ }^{I}$ Perm National Research Polytechnic University, Komsomolsky prospect, 29, Perm, 614990, Russia \\ ${ }^{2}$ Welding and Joining Institute, RWTH Aachen University, Aachen, 52062, Germany \\ ${ }^{3}$ Institute of Electronics, Bulgarian Academy of Sciences, 1 ,, 15 November “ Str., Sofia, 1040, Bulgaria \\ *Corresponding author E-mail: trushnikov.d.m@mail.ru
}

\begin{abstract}
Prospects of one of unconventional research areas aimed at improving additive technologies have been described. The key aspect of the proposed technology is the formation of multilayered homogeneous materials in vacuum using electric arc as a heating source, as well as using a solid metal wire as a filler metal. It is shown that this approach, compared to the available solutions applied in the global industrial production practices, will serve to increase productivity related to forming layerwise materials, as well as to resolve a number of disadvantages of the available equipment used for additive technologies implementation.
\end{abstract}

Keywords: Directed metal deposition; Hybrid additive technologies; Vacuum arc.

\section{Introduction}

Additive manufacturing (AM) is one of the top requested innovation technologies in aerospace industry now. Today additive technologies (AT) or technologies of layerwise synthesis are among the most dynamic research areas of "digital" manufacturing. They assist in a faster problem solving for preproduction, and, in some cases, they are often used to manufacture real products and represent key enabling technologies of this century $[1,2,3,4]$. The majority of the available additive technologies aimed at manufacturing metal products are based on using powder systems as a source material for product formation $[4,5,6,7,8]$. Wheras the range of construction materials which can be used to produce ready-made high quality products becomes truly small. In particular, the formation of products out of the majority of aluminum alloys, as well as alloys of active metals, such as titanium and magnesium alloys, lead to an increased material's porosity of a product with a considerate decrease of its mechanical characteristics $[9,10,11,12]$. The productivity of manufacturing workpieces made of powder materials within the available additive technologies is extemely low, which makes these technologies inapplicable for production of large scale workpieces.

The researches in the field of additive technologies, including wire-based materials, are active in the following companies: $3 \mathrm{D}$ Systems Corporation (U.S.), 3T RPD (U.K.), Arcam AB (Sweden), Biomedical Modelling, Inc. (U.S.), Envisiontec GmbH (Germany), EOS GmbH Electro Optical Systems (Germany), Fcubic AB (Sweden), GPI Prototype and Manufacturing Services, Inc. (U.S.), Greatbatch, Inc. (U.S.), Layerwise NV (Belgium), Limacorporate SPA (Italy), Materialise NV (Belgium), Medical Modeling, Inc. (U.S.) Norsk Titanium (U.S.), Sciaky (US).
According to ASTM F2792 [3] standard, AM processes have two categories: Directed Energy Deposition (DED) and Powder Bed Fusion (PBF). During AM such source materials as powder or wire, and such sources of energy as Laser (L), Electron Beam (EB), Plasma Arc (PA) or Gas Metal Arc (GMA) are used. Fig. 1 shows the schemes of AT using different source materials and heat sources [3].

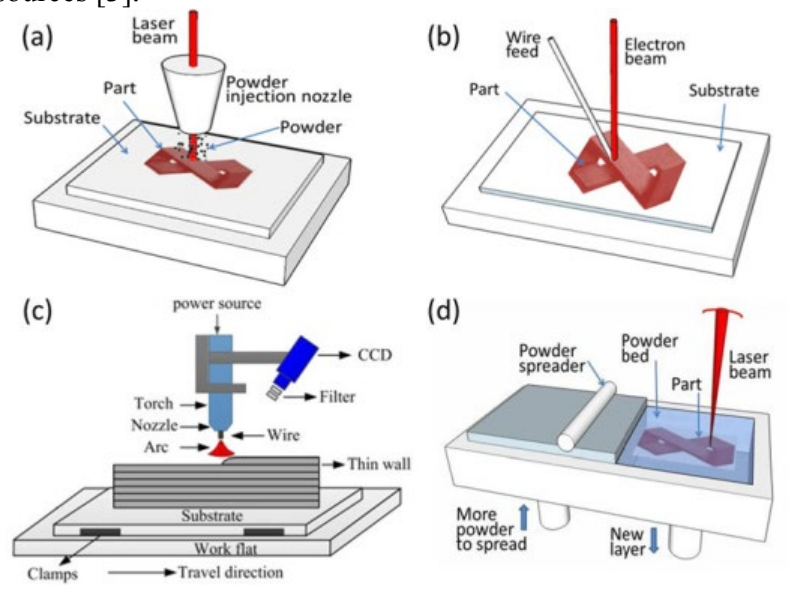

Fig. 1: Schematic representation of AT (a) DED-L, (b) DED-EB, (c) DED-GMA, (d) PBF-L [3]

\section{Direct Deposition of Wire Materials During Layerwise Synthesis of Large Scale Workpieces}

The wire-based formation of metal products is the key trajectory related to the development of additive technologies. This solution 
makes it possible to get rid of problems connected to a low productivity of the available methods, a high price of the equipment used, a limited range of materials used, which are typical for the traditional source material during additive formation, i.e. powder systems melted with a powerful heat source [13-15]. The prospects of developing the wire-based formation technologies are great, and they have not yet been revealed in the world.

It is known that there are some facilities which manufacture workpieces in vacuum using electron beam, which is quite a productive solution, when it comes to a large variety of advanced materials, in particular, reactive metals and their alloys. However, electron-beam systems have some disadvantages. First of all, it is the need to use high-voltage sources for an electron beam gun, staged pumping-out systems, in order to obtain high vacuum; in some cases during electron-beam processes, it is necessary to provide special protection for personnel against continuous X-ray radiation, which occurs when electron beam interacts with the processed material, which makes the service of facilities much more difficult. Nonsymmetric wire feeding into the interaction zone makes it difficult to provide the additive formation of workpieces with a complex shape. Apart from that, high price is one of disadvantages, both for the plant and its servicing.

In many cases, it is reasonable to create more simple and available plants for all sectors of industry, and, which is most important, more affordable and universal plants for additive manufacturing in vacuum, which will result in making the most of the available equipment's elements and technologies. Electric arch is one of the most common sources of heat during welding and deposition.

At the moment there is a great variety of welding methods used in Wire Arc Additive Manufacturing (WAAM) $[16,17]$. The general classification of WAAM depending on the methods of the layerwise synthesis of products using arc deposition is shown in Fig. $2[18,19,20,21]$.

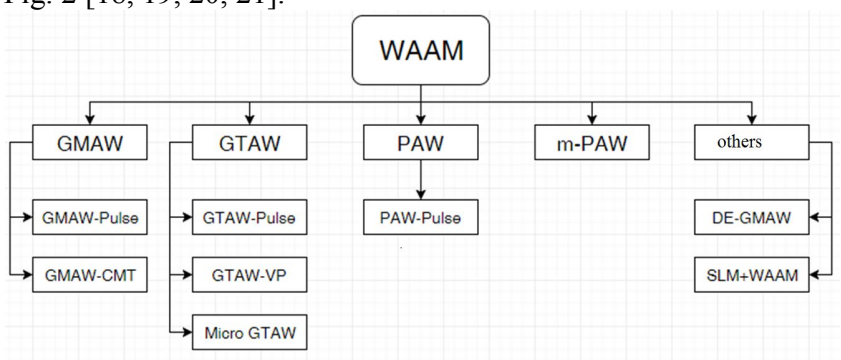

Fig. 2: Methods of arc deposition used for WAAM [18-21]

Application of arch and plasma sources for the wire-based deposition in hybrid technologies of layerwise synthesis has been intensely developing in the world. In 2016 Norsk Titanium, the Norwegian startup company, attracted an additional investment of $\$ 25$ million for the certification of the material obtained by the plasma layer-by-layer fusion of titanium wire to be used to manufacture parts of Boeing and Airbus aircrafts (Fig. 3).

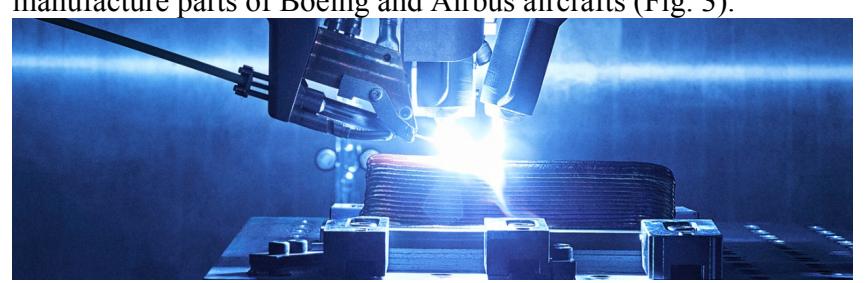

Fig. 3: The Rapid Plasma Deposition process involves metal wire feedstock and argon gas. Image by Norsk Titanium.

Also, WAAM company should be noted, based at Cranfield University, which develops technologies aimed at "growing" large-size products using plasma technologies or the surfacing technology using a melted electrode with an impulse wire feed and cold metal transfer (CMT) developed by Fronius. In mid-2016 LASSIM project was launched in Europe with a budget of about 5 million euros for three years, which combined 16 companies. The project's goal is to create a stand for the implementation of several processes of hybrid manufacturing of large raw parts at one place: additive manufacturing, multi-axis machining, layerwise strain hardening, measurement, non-destructive control.

\section{Prospects of Using Vacuum Arc Discharge in Additive Manufacturing of Metal Products}

The analysis of the existing situation shows that it is promising to combine the capabilities of the Sciaky (Fig. 4, 5) and Norsk Titanium (Fig. 6) providing a combination of the effective vacuum protection and the properties of the electric arc as a source of heat to create, on their basis, the arc additive technologies in vacuum [9, $13,14]$. The degree of a vacuum chamber discharge can be much less, than in the case of using electron beam as a source of heat (about $10^{-2} \ldots 10^{-1} \mathrm{~Pa}$ ), and the quality of protection will be higher, than in the case of using protective gases or chambers with controlled atmosphere in traditional arc technologies (at a pressure of $1.3 \mathrm{~Pa}$, the impurity content is $2 \ldots 2.5$ times less than in argon of the highest grade).

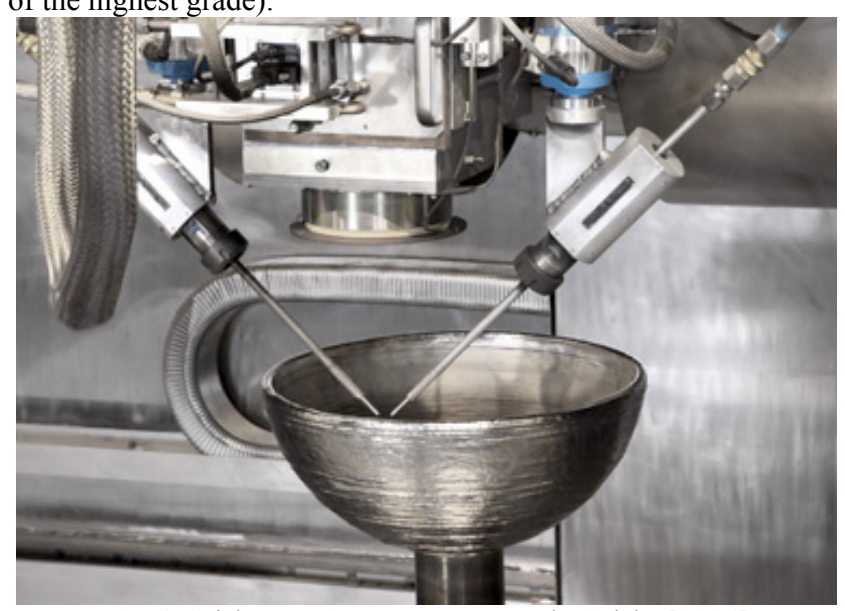

Fig. 4: Sciaky’s EBAM process. Image by Sciaky $[13,14]$

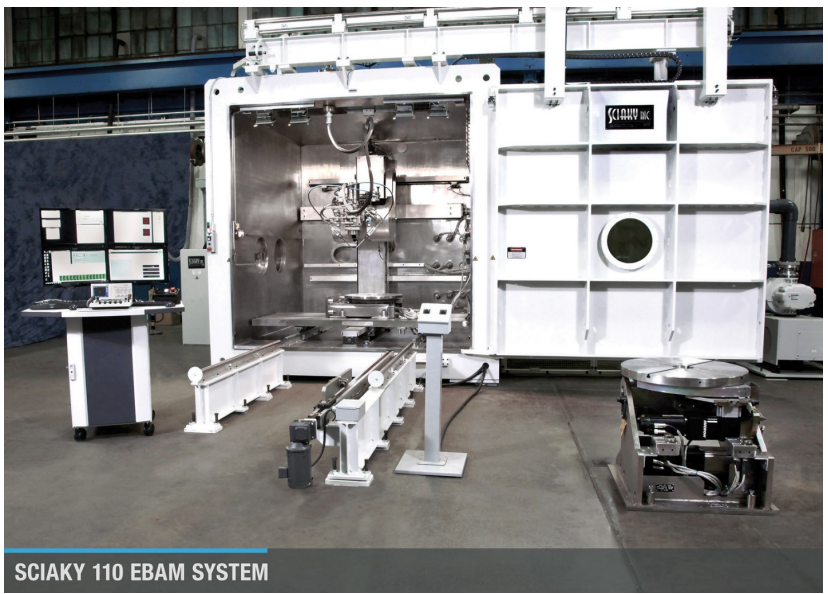

Fig. 5: A Sciaky EBAM 110 System $[13,14]$ 


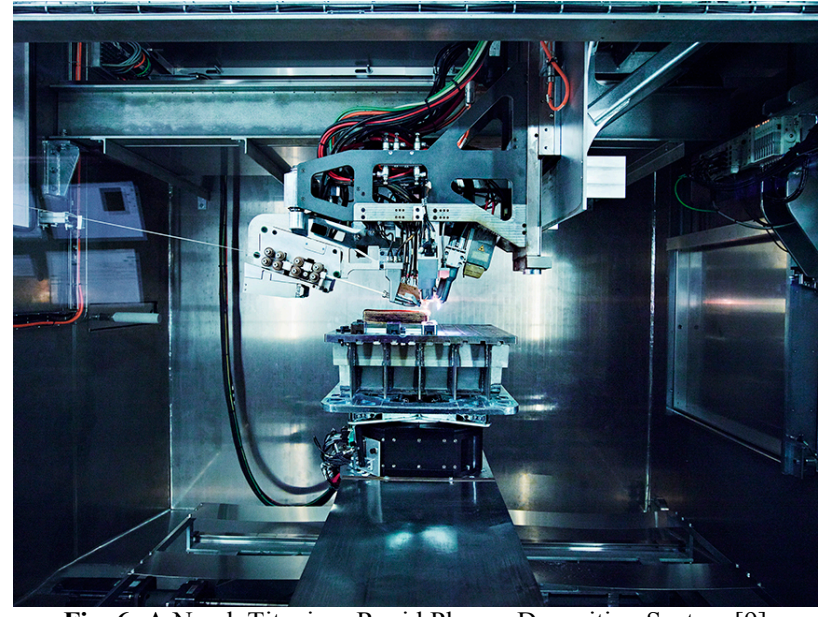

Fig. 6: A Norsk Titanium Rapid Plasma Deposition System [9]

Vacuum promotes intensive degassing and refining of a molten metal, which provides an increase in physical and mechanical properties of ready-made samples. From an economical point of view, vacuum, as a protective environment, has a number of advantages, in comparison with inert gases and, above all, the possibility of obtaining it directly at the workplace, thus only incurring power costs. The calculations show that the use of a vacuum chamber of more than $1 \mathrm{~m}^{3}$ is almost two times cheaper, than the chambers with the controlled atmosphere. When using vacuum protection, costs associated with the transportation of high-pressure tanks or cryogenic tanks are eliminated. Thus, the technology and equipment developed will make it possible to "grow" metal parts from steels, aluminum alloys, as well as, thanks to vacuum protection, from alloys of reactive metals, such as titanium, magnesium and other reactive, refractory and rare metals.

The development of this technology is complicated by a number of factors, both practical and theoretical ones, such as the lack of mathematical models connecting the technological parameters with the geometric characteristics of weld beads, due to a complex nature and non-linearity of the processes; a low stability of arc discharge in vacuum; difficulties in controlling the formation at non-stationary raw part's temperature during layerwise synthesis; metallurgical features in layerwise synthesis, especially when fusing non-similar materials during the formation of raw parts with functional gradient properties; and a relatively small heat release on a product with a large volume of electrode metal with a low heat content can lead to undercuttings and incomplete fusions (when using a consumable electrode).

Thus, a series of new problems arise, and they require new solutions. In order to increase the stability of discharge, it is reasonable to investigate the option of using the impulse wire feed with the feedback based on the potential in the wire. It will help to identify the moments of wire closing and opening and arc extinguishing. When a wire touches the product, it draws back until it interupts the contact, when a wire interrupts or during the arc extinguishing, the wire feed starts towards the main metal. The advantages of this process are in its self-regulation, the minimal thermal impact, the minimal splashing and an exceptionally stable arc. Previously this process has not been studied under vacuum deposition. An additional or alternative solution aimed at increasing the arc stability and providing a qualitative formation can be the use of a plasma source with a plasma-forming gas or a hollow cathode system.

In order to develop the scientific and technological principles aimed at manufacturing raw parts from special structural materials by the local fusion of wires with an electric arc in vacuum that ensure the physical and mechanical properties of a material at the level of materials of existing engineering products, it is necessary to combine the experimental and analytical methods based on the construction of physical and mathematical models, describing the mechanisms under study. It will be necessary to formalize the investigated processes of wire-based additive deposition in the form of a mathematical description of arc combustion in vacuum and additive synthesis of samples, creating mathematical models of formation and a stable existence of an electric arc in vacuum, heating, melting, heat and mass transfer followed by the crystallization of a wire material. Due to the development of the mathematical model of an arc discharge in vacuum during the additive manufacturing of samples under the deposition of the solid-metal filler, it will be possible to describe the process in a more comprehensive way. The formation of an arc discharge in vacuum is characterized by nonequilibrium plasma with a temperature of electrons that is orders of magnitude higher than the temperature of neutral atoms $[22,23,24]$. The mathematical model can be based on solving the system of transfer equations for concentration and average energy electrons $[25,26]$. The electric field is determined by the Poisson's equation. To describe the mass transfer of heavy plasma particles (ions, neutral unexcited and excited atoms), the mass transfer equation for a multicomponent mixture can be used [24, 25]. As the distance from the zone where the arc acts on the metal decreases, the plasma becomes collisionless, and the diffusion equations are transformed into the equation of continuity for charge, mass and energy. Apart from thermionic processes, it is necessary to take into account the Schottky effect, when calculating the electron emission value from the surface of a heated metal. The mathematical model of heat and mass transfer during wire-based additive manufacturing of products using electron beam in vacuum will consider phase and structural transitions, inhomogeneous thermal and physical characteristics of materials and distribution of additive agents.

The experimental works should include studies related to the influence of current polarity, electrode's shape and material, discharge degree in a chamber, the use of the plasma-forming gas and impulse wire filler with feedback based on formation stress, arc combustion stability and quality of the deposited layer during additive formation of layers using the method of wire local melting in vacuum. Also the team of authors is planning to conduct a series of multifactor experiments with various variables and fixed parameters. The variable parameters will be the feed rate of the material, power and speed of motion of the heat source. The fixed parameters will be the arc current polarity, chemical composition and geometrical characteristics of the fed material and ways of material feed (in front of the heating source, behind the heating source, vertical or horizontal feed). The controlled parameters of the experimental results' quality evaluation are physical and mechanical properties of the material synthesized by deposition (yield stress, ultimate strength, hardness, impact viscosity), as well as the absence of unacceptable internal defects (pores, cracks, incomplete fusions etc.) and conformity with the required geometrical sizes. Statistical methods of analysis are also possible for the optimization of technological processes.

\section{Conclusions}

The paper presents the justification of the new technological process which is the formation of multilayered homogeneous materials in vacuum using electric arc as a heating source, as well as using a solid metal wire as a filler metal. The problems which require solutions have been outlined for the proposed technology. The prospect of creating arc additive technologies in vacuum was shown. Practical and theoretical factors that restrain the development of technology were indicated. The directions of basic and applied researches necessary to achieve results were formulated. 


\section{Acknowledgement}

The reported study was partially supported by the Government of Perm Krai research project Nr. S-26/787 of December 21, 2017 (the formulation of tasks for the development of the process of direct arc metal deposition), by the grants from the Russian Foundation for Basic Research RFBR Nr. 18-08-01016 A (the formulation of basic tasks for the development of the process of direct arc metal deposition), as well as by Ministry of Education and Science of the Russian Federation at the base part of the state assignment Nr. 9.9697.2017/8.9 (the review of the existing technologies for direct metal deposition).

\section{References}

[1] Elliott JA (2011), Novel Approaches to Multiscale Modelling in Materials Science. International Materials Reviews 56, 207-225.

[2] Petrick I \& Simpson T (2013), Point of View: 3D Printing Disrupts Manufacturing: How Economies of One Create New Rules of Competition. Research-Technology Management 56(6), 15-16.

[3] Morrow WR, Qi H, Kim I, Mazumder J \& Skerlos SJ (2007), Environmental Aspects of Laser-Based and Conventional Tool and Die Manufacturing. Journal of Cleaner Production 15, 932-943.

[4] Wray P (2014), Additive Manufacturing: Turning Manufacturing Inside Out. American Ceramic Society Bulletin 93(3), 17-23.

[5] Freedman DH (2012), Layer by Layer. MIT Technology Review 115(1), 50-53.

[6] Qi H. B, Yan YN, Lin F, He W, Zhang RJ (2006), Direct metal part forming of 316L stainless steel powder by electron beam selective melting. Proceedings of the Institution of Mechanical Engineers, Part B. Journal of Engineering Manufacture 220(11), 1845-1853.

[7] Murr LE, Gaytan SM, Ramirez DA, Martinez E, Hernandez J, Amato KN, Shindo PW, Medina FR \& Wicker RB (2012), Metal fabrication by additive manufacturing using laser and electron beam melting technologies. Journal of Materials Science \& Technology 28(1), 1-14.

[8] Frazier WE (2014), Metal Additive Manufacturing: A Review. Journal of Materials Engineering and Performance 23(6), 917-928.

[9] Louvis E, Fox P \& Sutcliffe ChJ (2011), Selective laser melting of aluminium components. Journal of Materials Processing Technology 211(2), 275-284.

[10] Campanelli SL, Contuzzi N, Angelastro A \& Ludovico AD (2010), Capabilities and Performances of the Selective Laser Melting Process. New Trends in Technologies: Devices, Computer, Communication and Industrial Systems.

[11] Bezobrazov IuA, Zlenko MA, Zotov OG \& Kolbasnikov NG (2012), Analiz struktury obraztsov, poluchennykh DMLS- i SLMmetodami bystrogo prototipirovaniia [The analysis of the structure of samples obtained by DMLS- and SLM-methods of fast prototyping]. Materialy 6-i Mezhdunarodnoi molodezhnoi nauchnoprakticheskoi konferentsii "Innovatsionnye tekhnologii v metallurgii i mashinostroenii”, Ekaterinburg, 154-157.

[12] Qiu Ch, Panwisawas Ch, Ward M, Basoalto HC, Brooks JW \& Attallah MM (2015), On the role of melt flow into the surface structure and porosity development during selective laser melting, Acta Materialia 96, 72-79.

[13] Sciaky Inc, Electron Beam Additive Manufacturing (EBAM) Advantages of Wire AM vs. Powder AM. http://additivemanufacturing.com/2015/10/14/electron-beamadditive-manufacturing-ebam-advantages-of-wire-am-vs-powder$\mathrm{am} /$

[14] Sciaky Inc, Electron Beam Additive Manufacturing (EBAM) $\mathrm{http}: / /$ www.sciaky.com/images/pdfs/product-sheets/Sciaky-EBAMTechnology.pdf

[15] Jhavar S, Jain NK \& Paul CP (2014), Development of microplasma transferred arc ( $\mu$-PTA) wire deposition process for additive layer manufacturing applications. Journal of Materials Processing Technology 214(5), 1102-1110.

[16] Spencer DJ, Dickens PM (1998), W.C. Rapid prototyping of metal parts by three dimentional welding. Mech E J. Eng. Manuf, 212, $175-182$.

[17] Ding J, Colegrove P, Martina F, Williams S, Wiktorowicz R \& Palt MR (2015), Development of a laminar flow local shielding device for wire + arc additive manufacture. Journal of Materials Processing Technology 226, 99-105.
[18] Song YA \& Park S (2006), Experimental investigations into rapid prototyping of composites by novel hybrid deposition process. Journal of Materials Processing Technology 171(1), 35-40.

[19] Ding J, Colegrove P, Mehnen J, Williams S, Wang F \& Almeida PS (2014), A computationally efficient finite element model of wire and arc additive manufacture. The International Journal of Advanced Manufacturing Technology 70, 227-236.

[20] Aiyiti W, Xiang L, Zhang LZh \& Chen RM (2012), Study on the Veritable Parameters Filling Method of Plasma Arc Welding Based Rapid Prototyping. Key Engineering Materials 522, 110-116.

[21] Song Y-A, Park S, Hwang K, Choi D \& Jee H (1998), 3D Welding and Milling Direct Prototyping of Metallic Parts. Proceedings of the Solid Freeform Fabrication Symposium, University of Texas at Austin, 495-501.

[22] Toya HI, Hieda K \& Saitou T (2006), Preliminary Study on Arc Welding in Vacuum. Discharges and Electrical Insulation in Vacuum. ISDEIV'06. International Symposium on IEEE, 2, 762765

[23] Musa G, Betiu N, Mustata I, Baltog A \& Popescu A (1983), Low Voltage Arc Weldingin Vacuum. Revue Roumaine de Physique 28(10), 907-908.

[24] Suitaetal Y (1994), Welding International, 8(4), 269-273.

[25] Trushnikov DN \& Mladenov GM (2015). Numerical model of the plasma formation at electron beam welding. Journal of Applied Physics 117(1), 013301

[26] Toya H et. al (2002), $20^{\text {th }}$ Int. Symp. On Discharges and Electrical Insulation in Vacuum (Tours, France), 327-330. 